\title{
Tumoración muy destructiva
}

\author{
Tanilu C. Grande-Montalvo ${ }^{a}$ y Cristina Faura-Berruga ${ }^{b}$
}

a Departamento de Medicina

Familiar y Comunitaria.

Centro de Salud Zona 1.

Gerencia de Atención Primaria

de Albacete. España.

${ }^{b}$ Departamento de

Dermatología y Venereología.

Complejo Hospitalario

Universitario de Albacete.

Albacete. España.

Correspondencia:

Tanilu C. Grande-Montalvo.

CS Zona 1. C/ José María

Sánchez lbáñez, S/N.

Código postal 02006,

Albacete. España.

Correo electrónico:

tanilu_grande@yahoo.com

Recibido el 6 de febrero de 2014.

Aceptado para su publicación el 21 de marzo de 2014.

\section{RESUMEN}

El carcinoma basocelular es la neoplasia maligna más frecuente en el ser humano. Se caracteriza por ser localmente invasivo y de crecimiento lento. Presentamos el caso de un paciente con un carcinoma basocelular avanzado, que le causó una marcada destrucción de la región nasal y que por ello no fue susceptible de tratamiento quirúrgico o radioterapia. Para este tipo de pacientes se propone una nueva terapia innovadora, el Vismodegib, una molécula que inhibe la proliferación tumoral y que ha supuesto un gran avance en el manejo de estos pacientes.

Palabras clave: Carcinoma basocelular. Destrucción cutánea. Vismodegib. Vía de señalización Hedgehog.

\section{ABSTRACT}

\section{A highly destructive tumour}

The basal-cell carcinoma is the most frequent cancer in human beings. It is characterized by being locally invasive and slow-growing. We present the case of a patient with basal cell carcinoma which caused a marked destruction of the nasal region, for which reason he could not be treated surgically or with radiotherapy. For this type of patient, a new innovative therapy is proposed: Vismodegib, a molecule which inhibits the spreading of the tumour and which has signified a great advance in the management of these patients.

Key words: Basal-cell carcinoma. Cutaneous destruction. Vismodegib. Hedgehog pathway.

\section{INTRODUCCIÓN}

El carcinoma basocelular (CB) es el cáncer más frecuente en los seres humanos y representa aproximadamente el $75 \%$ de todos los cánceres cutáneos no melanomas ${ }^{1}$.

Característicamente, se presenta en regiones anatómicas fotoexpuestas, es asintomático y localmente muy invasivo, llegando a ser muy destructivo si no se trata adecuadamente.

\section{OBSERVACIONES CLÍNICAS}

Se trata de un varón de 83 años de edad, que en 2003 fue derivado desde nuestra consulta de Atención Primaria a la consulta de Dermatología por presentar tres lesiones nasales asintomáticas, de tres años de evolución. Una de ellas, de medio centímetro, en la región de la punta nasal izquierda, erosionada y con centro costroso (figura 1); las otras, en la región paranasal y en el ala nasal derecha, con bordes perlados y telangiectasias arboriformes (figura 2).

Se realizó la biopsia de las lesiones cutáneas y el diagnostico anatomopatológico fue de carcinoma basocelular macronodular. Tras la propuesta de extirpación radical de los tumores, el paciente se negó a dicho tratamiento. Posteriormente, fue ingresado en una residencia de ancianos tras desarrollar 


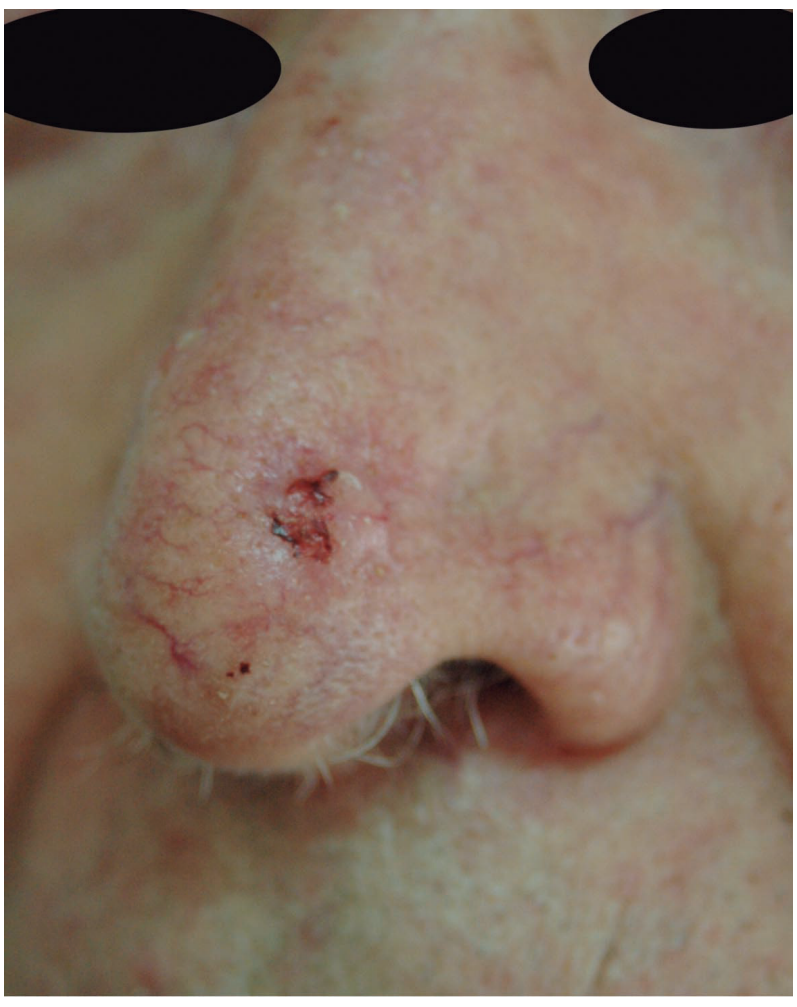

Figura 1. Lesión inicial en la punta nasal

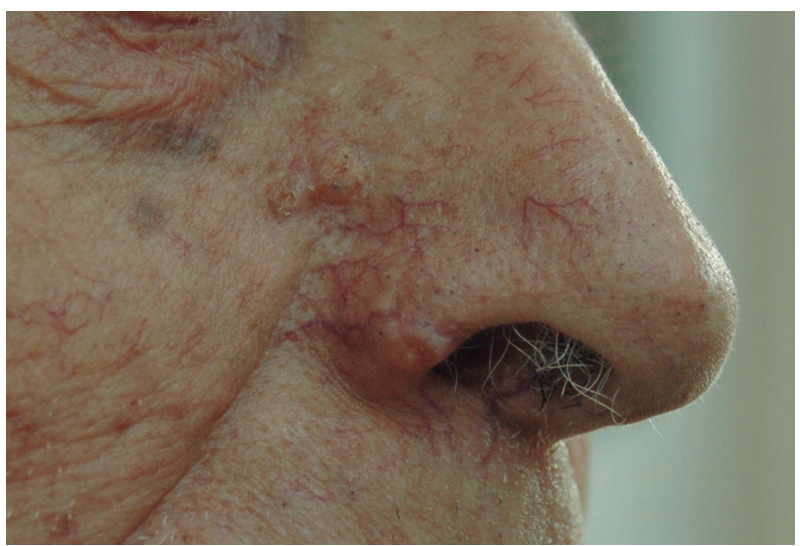

Figura 2. Lesión inicial en la región paranasal y en el ala nasal derecha

una demencia alcohólica y no volvió a tener contacto con su Centro de Salud, ya que el paciente seguía negándose al tratamiento de su patología y no estaba incapacitado legalmente para la toma de decisiones.

Transcurridos 10 años del diagnóstico acudió de nuevo a la consulta presentando ya una marcada destrucción cutánea y cartilaginosa de todo el dorso nasal y ala nasal derecha, con sangrado y costras mielicéricas en la superficie (figura 3); no se palpaban adenopatías patológicas locorregionales.

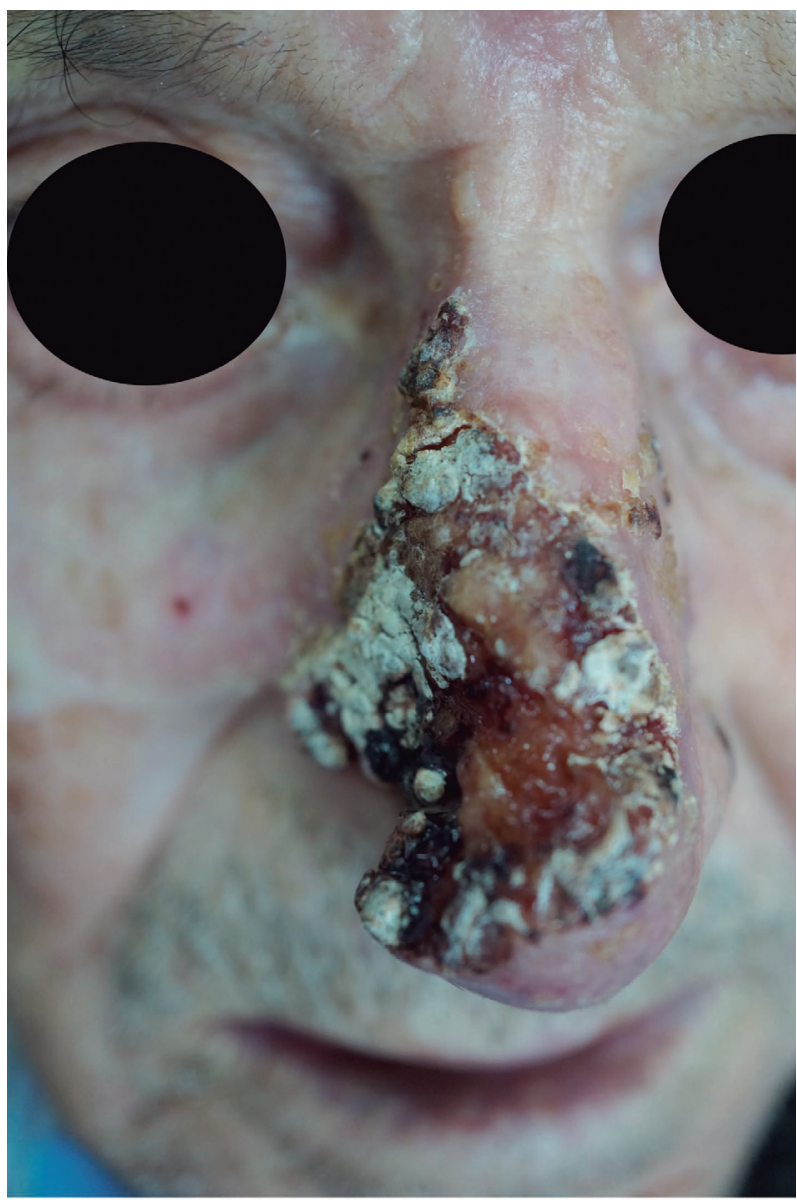

Figura 3. Lesión final con destrucción cutánea y cartilaginosa de todo el dorso nasal y ala nasal derecha

Tras los hallazgos clínicos y los resultados de las pruebas complementarias, se llegó al diagnóstico de carcinoma basocelular localmente invasivo. El paciente fue valorado por parte del servicio de Dermatología y Cirugía Maxilofacial, donde se concluyó que debido al avanzado estado de la neoplasia resultaba desde el punto de vista quirúrgico inoperable.

\section{COMENTARIOS}

El carcinoma basocelular es una neoplasia maligna derivada de células no queratinizadas que se originan en la capa basal de la epidermis ${ }^{1}$. En términos generales, se caracteriza por ser localmente invasivo, de crecimiento lento y con escaso riesgo de metástasis a distancia, sin embargo, si no es tratado oportunamente, es capaz de provocar gran destrucción locorregional.

El tumor se desarrolla habitualmente en la piel expuesta al sol como es la región facial, siendo la na- 
riz el lugar con el porcentaje más alto de lesiones (20,9\%). Es más frecuente en individuos de edad avanzada, varones y con fototipos cutáneos I y II. La gran mayoría de los CB ocurren de forma esporádica, aunque también pueden ser hereditarios (en el síndrome de Gorlin y en el xeroderma pigmentoso) ${ }^{2}$.

Existen 5 formas de presentación clínica de los $\mathrm{CB}^{1}$ :

- El CB de tipo nodular es la forma más común de todas; son como pápulas o nódulos transparentes o perlados, del color de la piel o eritematosos, con superficie suave, bien delimitados y firmes.

- El de tipo ulcerativo, donde se observa además una úlcera, generalmente cubierta por una costra con un borde infiltrado.

- El esclerosante, que se presenta como un pequeño parche de piel de características morfeiformes simulando una cicatriz superficial, poco definida, del color de la piel.

- El multicéntrico superficial, donde las lesiones se presentan como placas delgadas, rosas o rojas y con un característico borde filiforme y telangiectasias.

- El pigmentado, que puede ser desde lesiones marrones hasta azules o negros, de superficie suave y brillante y de consistencia dura y firme.

En cuanto al diagnostico, es básicamente clínico y se confirma con el análisis anatomopatológico de la pieza cutánea.

Respecto al tratamiento del CB, los tratamientos convencionales consiguen unas altas tasas de curación. Los $\mathrm{CB}$ superficiales (según las guías de la National Comprehensive Cancer Network) ${ }^{3}$ pueden ser tratados con imiquimod tópico, 5-fluorouracilo tópico, terapia fotodinámica con ácido aminolevulíco o metillevulinato, curetaje y electrocoagulación, crioterapia o con extirpación quirúrgica. Los CB con alto riesgo de progresión (subtipos nodulares o infiltrativos) se tratan con escisión quirúrgica o cirugía de Mohs.

Sin embargo, en un porcentaje pequeño de pacientes (en torno al $1 \%$ ), el CB progresa, bien avanzando localmente, haciendo imposible su extirpación quirúrgica (como en el caso de nuestro paciente), o bien metastatizando ${ }^{3}$. Por otra parte, en pacientes con síndrome de Gorlin que pueden desarrollar múltiples CB a edades muy tempranas, el tratamiento quirúrgico convencional puede llegar a ser muy mutilante, provocando una gran alteración funcional, estética y de la calidad de vida de estos pacientes. Se ha visto que la radioterapia puede controlar el CB de forma locorregional durante 4 años hasta en un $86 \%$ de los casos, con un tiempo medio hasta la recurrencia de 40,5 meses $^{4}$. Sin embargo, está contraindicada en el síndrome de Gorlin y en carcinomas basocelulares recurrentes tras radioterapia ${ }^{5,6}$.

Recientemente se ha descrito Vismodegib (GDC0449), una molécula de administración oral que actúa a nivel de la vía de señalización Hedgehog, implicada en el desarrollo de numerosas neoplasias, con actividad antitumoral en los carcinomas basocelulares localmente invasivos o metastási$\cos ^{7}$. En el ser humano, la vía de señalización Hedgehog $(\mathrm{Hh})$ es un elemento crítico en la regulación del desarrollo y formación de estructuras como el sistema nervioso, huesos, pulmones, piel, pelo y células pluripotenciales durante el desarrollo embrionario. En la vida adulta, la vía de señalización $\mathrm{Hh}$ se encuentra inactiva en todas las células, con la excepción del pelo, piel y células pluripotenciales, para permitir su mantenimiento ${ }^{8}$. Sin embargo, se ha visto que su activación aberrante, causada por mutaciones, juega un papel importante en el inicio de ciertas neoplasias ${ }^{9}$. La mayoría de los CB esporádicos y todos los que aparecen en el síndrome de Gorlin y en el xeroderma pigmentoso se ha comprobado que contienen mutaciones en la vía de señalización $\mathrm{Hh}$, generalmente inducidas por los rayos UV ${ }^{10}$.

En enero del 2012 la U.S. Food and Drug Administration (FDA) aceptó el uso de Vismodegib oral como el primer fármaco disponible para el tratamiento del CB avanzado o metastásico en adultos no subsidiarios de tratamiento quirúrgico. En España, actualmente solo se puede utilizar dentro de ensayos clínicos o solicitando dicha medicación como uso compasivo. En nuestro caso clínico, debido a que el paciente cumple las indicaciones para el uso compasivo de dicho fármaco, se le administrará en breve, en cuanto se disponga de la medicación extranjera.

En conclusión, presentamos un caso en el que se destaca la agresiva evolución clínica de un carcinoma basocelular nasal que, aunque quirúrgicamente sería inoperable, puede ser tratado gracias al descubrimiento del fármaco Vismodegib, que ha supuesto un gran avance en el manejo de estos pacientes, aumentando su supervivencia y su calidad de vida. 


\section{BIBLIOGRAFÍA}

1. Wolff K, Goldsmith L, Katz S, Gilchrest B, Paller A, Leffell $\mathrm{D}$ (eds). Fitzpatrick's Dermatology in General Medicine, 7th Edition. New York: McGraw-Hill; 2008.

2. López Estebaranz JL. Tratamiento del carcinoma basocelular invasivo o la vía del erizo. Piel (Barc). 2012;27(8):425428.

3. National Comprehensive Cancer Network. Basal Cell and Squamous Cell Skin Cancers, Version 1. 2011. Disponible en: http://www.nccn.org/professionals/physician_gls/f guidelines.asp\#nmsc. [Consultado el 01/04/2014]

4. Kwan W, Wilson D, Moravan V. Radiotherapy for locally advanced basal cell and squamous cell carcinomas of the skin. Int J Radiat Oncol Biol Phys. 2004;60(2):406-11.

5. Loncaster J, Swindell R, Slevin F, Sheridan L, Allan D, Alan E. Efficacy of photodynamic therapy as a treatment for Gorlin syndrome-related basal cell carcinomas. Clin Oncol (R Coll Radiol). 2009;21(6):502-8.
6. Telfer NR, Colver GB, Morton CA. Guidelines for the management of basal cell carcinoma. $\mathrm{Br} J$ Dermatol.2008;159(1):35-48.

7. Robarge KD, Brunton SA, Castanedo GM, Cui Y, Dina MS, Goldsmith R et al. GDC-0449-a potent inhibitor of the hedgehog pathway. Bioorg Med Chem Lett. 2009;19(19):557681.

8. Rubin LL, De Sauvage FJ. Targeting the hedgehog pathway incancer. Nat Rev Drug Discov. 2006;5(12):1026-33.

9. Von Hoff DD, LoRusso PM, Rudin CM, Reddy JC, Yauch $\mathrm{RL}$, Tibes $\mathrm{R}$, et al. Inhibition of the Hedgehog pathway in advanced basal cell carcinoma. $N$ Engl $J$ Med. 2009;361(12):1164-72.

10. Johnson RL, Rothman AL, Xie J, Goodrich LV, Bare JW, Bonifas JM et al. Human homolog of patched, a candidate gene for the basal cell nevus syndrome. Science. 1996;272(5268):1668-71. 